\title{
RISK AND PROTECTIVE FACTORS IN THE ORIGIN OF ATRIAL SEPTAL DEFECT SECUNDUM - NATIONAL POPULATION-BASED CASE-CONTROL STUDY
}

\author{
Melinda Csáky-Szunyogh ${ }^{1}$, Attila Vereczkey², Róbert Urbán ${ }^{3}$, Andrew E. Czeizel ${ }^{4}$ \\ ${ }^{1}$ National Centre for Healthcare Audit and Inspection, Budapest, Hungary \\ ${ }^{2}$ Versys Clinics, Human Reproduction Institute, Budapest, Hungary \\ ${ }^{3}$ Eötvös Loránd University, Institute of Psychology, Budapest, Hungary \\ ${ }^{4}$ Foundation for the Community Control of Hereditary Diseases, Budapest, Hungary
}

\begin{abstract}
SUMMARY
The aim of this study was to assess the risk factors in the origin of lethal or surgically corrected isolated atrial septal defect secundum. The population-based Hungarian Case-Control Surveillance of Congenital Abnormalities (conducted between 1980 and 1996) comprised 472 atrial septal defect secundum cases, 678 matched controls and 38,151 available controls without any defects; in addition, 21,022 malformed controls with other isolated defects. Medically recorded chronic disorders in the prenatal maternity logbook were evaluated, while acute maternal diseases, drug treatments and pregnancy supplements were analyzed on the basis of both prospective medically recorded data and retrospective maternal information. Acute pelvic inflammatory disease, paroxysmal supraventricular tachycardia and phenolphthalein treatment due to severe constipation of mothers were shown to contribute to the development of atrial septal defect secundum of their children. High doses of folic acid in early pregnancy had positively influenced a minor part of isolated atrial septal defect secundum in foetuses. In conclusion, the obvious genetic predisposition for atrial septal defect secundum is connected with maternal paroxysmal supraventricular tachycardia and triggered by acute pelvic inflammatory diseases and phenolphthalein treatment, while the manifestation of atrial septal defect secundum can be reduced by high doses of folic acid supplementation in early pregnancy.
\end{abstract}

Key words: single atrial septal defect secundum, pregnancy, acute pelvic inflammatory disease, supraventricular tachycardia, phenolphthalein, folic acid

Address for correspondence: A. E. Czeizel, Foundation for the Community Control of Hereditary Diseases, H-1026, Törökvész lejtő 32, Budapest, Hungary. E-mail: czeizel@interware.hu

\section{INTRODUCTION}

Structural birth defects, i.e. congenital abnormalities (CAs), represent a special category of disorders due to their very early onset and defect condition, in general, without chance for complete recovery. CAs of heart and great vessels, i.e. congenital heart defects (CHDs), represent the most prevalent and severe group of CAs. Among 1,000 live-births, 4-50 are affected by CHD in diverse studies; a relatively high variance in birth prevalence derives from the different age at examination and the sensitivity of the examination technique (1-5). In a Hungarian populationbased study of 2,259 children, based on the paediatric cardiologic examination and/or the evaluation of autopsy of each child, 10.2 per 1000 birth prevalence of CHDs was found (6).

There are both good and bad news in the medical field of CHDs. The good news is that the care of infants/children with CHD has been revolutionized over the last decades with a much better chance for their survival (7). The bad news is that the underlying causes of CHDs are still obscured. Without identifying the risk factors, prevention strategies cannot be developed. Recent progress in human genetics has resulted in the rapid identification of genes causing CHDs (8), however, the role of possible environmental factors in the origin of CHDs is unclear in the vast majority of patients (9).

Among CHDs, atrial septal defect (ASD) belongs to the most frequent CHD-groups with the birth prevalence 0.74 per 1,000 in Hungary (1). Studies in other countries estimated the birth prevalence of ASD 1 per 1,500 live-births explaining about $10 \%$ of CHDs (7). However, ASD comprises several anatomic types (10-12): CA of the ostium secundum is in the position of the foramen ovale, thus this CA represents true absence of the septal tissue. This ostium secundum (fossa ovalis) ASD, i.e. ASD secundum is abbreviated as ASD-II. The ostium primum defect of ASD is a communication in the lower part of the septum; this endocardial cushion type of ASD is called septum primum type of ASD and considered a partial form of atrioventricular septal defects. ASD may occur posteriorly between the right atrium and the sinus venosus, some right pulmonary veins may carry arterialized blood directly into the right atrium in this sinus venous ASD type. The complete absence of the entire atrial septum may also occur and it is called single or common atrium. ASD-II is the most frequent type of ASD, representing 85\% of all ASD (7).

Our study included only patients with isolated surgically corrected ASD-II, in order to evaluate cases affected with ASD-II 
as homogenous as possible in the population-based Hungarian Case-Control Surveillance of Congenital Abnormalities. The aim of the previous study was the evaluation of birth outcomes of patients with ASD-II (13) while the objective of this study is to estimate the possible causal risk factors in the origin of ASD-II

\section{MATERIALS AND METHODS}

\section{The Hungarian Case-Control Surveillance of Congenital Abnormalities (HCCSCA)}

HCCSCA (14) is based on the comparison of exposures between the mothers of patients with CA and controls without CA during pregnancy.

Patients with CA, i.e. cases including ASD-II in the HCCSCA were selected from the Hungarian Congenital Abnormality Registry (HCAR) (15). Reporting of CA cases to HCAR is mandatory for physicians, and most cases are reported by obstetricians and paediatricians. Autopsy was mandatory for all infant deaths and pathologists sent a copy of the autopsy report to HCAR if defects were identified in infant deaths. Since 1984 prenatal diagnostic centers have been asked to report malformed foetuses diagnosed prenatally with or without termination of pregnancy to HCAR. The recorded total (birth + foetal) prevalence of cases with CA was 35 per 1,000 informative offspring (live-born infants, stillborn foetuses and electively terminated malformed foetuses) between 1980 and 1996 (15) and about $90 \%$ of major CA were recorded in HCAR (16).

Only those cases reported to HCAR in the first 3 months after birth or elective termination of pregnancy were selected from HCAR records for HCCSCA. These cases represent $77 \%$ of cases recorded in HCAR (23\% of cases had mainly mild CA). In addition, cases with CA-syndromes caused by gene mutations or chromosomal aberrations with preconception origin were excluded.

Controls were defined as newborn infants without diagnosed CAs. The source of these controls for HCCSCA was the National Birth Registry of the Central Statistical Office. In general, two controls were matched to every case according to sex, birth week when the infant was born and district of parents' residence.

There were three sources of exposure data in HCCSCA:

1. Prospective medically recorded data. A letter was mailed continuously to the address of cases' and controls' mothers immediately after their selection for HCCSCA to explain the purposes of HCCSCA, and to request the prenatal maternity logbook, discharge summary of their delivery and every medical record concerning their diseases during pregnancy and their child's CAs. (These documents were sent back within 4 weeks.) Prenatal care for pregnant women in Hungary has been mandatory since 1951, thus nearly $100 \%$ of pregnant women visited prenatal care, on average 7 times during their pregnancy. The first visit was between the 6th and 12th gestational week calculated from the first day of the last menstrual period. Obstetricians in prenatal care recorded all pregnancy complications, maternal diseases and related medicinal products in women during pregnancy in the logbook.

2. Retrospective maternal self-reported information. A structured questionnaire with a list of drugs and diseases and a printed informed consent form were also mailed to cases' and controls' mothers. The questionnaire requested information on, among others, maternal diseases and medicine (drug and pregnancy supple- ment) intakes during pregnancy according to gestational month. In order to standardize the answers, mothers were asked to read the enclosed lists of medicinal products and diseases before they filledin the questionnaire and send it back with signed informed consent.

The mean \pm S.D. time elapsed between the end of pregnancy and return of the "information package" (including logbook, discharge summary, questionnaire, and informed consent) in our prepaid envelope was $3.5+2.1$ and $5.2 \pm 2.9$ months in cases and controls, respectively.

3. Supplementary data collection. Regional district nurses were asked to visit all case mothers who did not respond and help them to fill-in the same questionnaire and evaluate the available medical documents. Unfortunately district nurses could visit only 200 nonrespondent (17) and 600 respondent control mothers (18) as a part of two validation studies, because the ethics committee considered this follow-up to be disturbing for the parents of all healthy children.

Thus exposure information was available for $96.3 \%$ of cases (84.4\% from replies and $11.9 \%$ from visits) and $83.0 \%$ of controls (81.3\% from replies and $1.7 \%$ from visits). Signed informed consent was sent back by $98 \%$ of mothers, the name and address were deleted in $2 \%$ of subjects without signed informed consent.

The method of data collection changed in 1997. Since then all cases' and controls' mothers have been visited and questioned at home by regional nurses. These data have not yet been validated, therefore, only the 17 years' data set of HCCSCA (1980-1996) is evaluated in this study.

\section{Study Design of Cases with ASD-II}

The major evaluation problem of CHDs was that, in general, cases with CA were reported immediately after birth to HCAR and about $50 \%$ of cases with CHD were reported as unspecified CHDs, because the exact diagnosis of CHDs needed further examinations. Medical data of cases with CA were collected in HCCSCA 3.5 + 2.1 months later thus we were able to get specified CHD diagnoses in further $20 \%$ of cases. However, $30 \%$ of our CHD cases had no specified diagnosis in HCCSCA. Most live-born cases with CHD were cared or had surgical intervention in the paediatric cardiologic institutions in Hungary, therefore, one of the authors of this paper - Melinda Csáky-Szunyogh visited these cardiologic in- and outpatients clinics in 2008. Medical records were reviewed and the previous diagnosis of specified CHDs was checked (and corrected if necessary), unspecified CHDs were modified to specified CHD diagnoses. If cases with unspecified CHD diagnosis were not found in the records of paediatric cardiologic institutions, we correspond with their mothers to clarify the fate and/or diagnosis of these cases in 2009 and 2010. However, if these cases were not found or mothers refused the collaboration, they were excluded from the study.

At the evaluation of ASD-II there were 4 selection steps:

I. Cases with syndromic ASD due to major mutant genes such as CA-syndromes (e.g. Holt-Oram) or chromosomal aberrations (e.g. Down syndrome) and unclassified multiple CAs including ASD were excluded from the study.

II. Complex CHDs including ASD, e.g. specified Lutembacher syndrome (ASD associates with stenosis of mitral valve), or the combinations of ASD with other CHD, e.g. ventricular septal defect, were also excluded from the study.

III. Among ASD cases, only ASD-II was included into the study as mentioned above. 
IV. The clinical severity of ASD-II is wide. Many children have no symptoms, thus seem to be healthy, while large ASD-II is permitting a huge amount of blood to pass through to the right side of heart, the right atrium, right ventricle and lung will become overworked and pulmonary hypertension with right heart dilatation and atrial arrhythmia in later life may be lethal. On the other hand, some patients have spontaneous closure of ASD-II. Thus, finally, only ASD-II cases with lethal outcome or surgically corrected were included to the study, therefore, our cases represent a homogeneous group of severe manifestation of isolated ASD-II.

The onset of the closure of foramen ovale is after birth; however, missing of the closure is connected with pathological condition of atrial septum in the early phase of embryological development (19). The possible association of ASD-II with teratogenic factors was found mainly between the 6th and 9th postconception week, thus, we considered the critical period of ASD-II between the 8th and 11th gestational week, i.e. second and third gestational months.

Controls were divided into two groups: controls without CA matched to cases with ASD-II; and all population controls without CA in the dataset of HCCSCA. However, we had a third control group including cases with other isolated non-cardiac CAs, as malformed controls.

\section{Statistical Analysis}

SAS version 8.02 (SAS Institute, Cary, North Carolina, USA) was used for statistical analysis of data. First, we compared maternal characteristics to select confounders such as age, birth order and employment status as the indicator of socio-economic status (20). These data were reported in our previous paper (13). Conditional logistic regression models were used to estimate the relative risk (odds ratio: OR) with 95\% confidence intervals (CI) of ASD-II associated with maternal exposures during pregnancy in the group of cases compared with their matched controls. At the comparison of different maternal exposures during pregnancy in the group of cases with ASD-II and population controls or malformed controls, unconditional logistic regression model was used.

\section{RESULTS}

Our population-based data set included 472 cases with ASD-II, in addition, 678 matched controls and 38,151 all controls without CA as well as 21,022 malformed controls with other isolated CA. Of 472 cases, one stillborn foetus occurred with specified ASD-II diagnosis.

Among acute maternal diseases, including influenza, common cold with secondary complications, respiratory and digestive system, urinary tract and genital organs, only one specified group of genital organs' diseases showed a higher occurrence during the second and/or third gestational month in case mothers than in control mothers. Acute pelvic inflammatory diseases (all prospectively and medically recorded in the prenatal maternity logbook) occurred during this time window in mothers of 8 cases with ASD-II (1.7\%), while the incidence of it was $0.0 \%$ (none in mothers), 0.1\% (31 mothers, OR with 95\% CI: 21.2, 9.7-46.4) and $0.0 \%$ (8 mothers, 45.3, 19.9-121.2) in the groups of matched, all control and malformed controls.

All chronic maternal diseases evaluated in the study were medically recorded in the prenatal logbook (Table 1). Two disorders showed an association with the higher risk of ASD-II. Of 10 mothers with conduction disturbance in heart, 8 had paroxysmal supraventricular tachycardia while one was affected with

Table 1. Prevalence rate of medically recorded chronic diseases at least in 3 case mothers, matched control mothers, population control mothers, and malformed control mothers

\begin{tabular}{|c|c|c|c|c|c|c|c|c|c|c|c|}
\hline \multirow[t]{2}{*}{ Maternal diseases } & \multicolumn{2}{|c|}{$\begin{array}{l}\text { Case mothers } \\
\qquad(\mathrm{N}=472)\end{array}$} & \multicolumn{3}{|c|}{$\begin{array}{l}\text { Matched control mothers } \\
\qquad(\mathrm{N}=678)\end{array}$} & \multicolumn{3}{|c|}{$\begin{array}{l}\text { Population control mothers } \\
\qquad(\mathrm{N}=38,151)\end{array}$} & \multicolumn{3}{|c|}{$\begin{array}{l}\text { Malformed control mothers } \\
\qquad(\mathrm{N}=21,022)\end{array}$} \\
\hline & No. & $\%$ & No. & $\%$ & OR, $95 \% \mathrm{Cl}^{*}$ & No. & $\%$ & OR, $95 \% \mathrm{Cl}^{*}$ & No. & $\%$ & OR, $95 \% \mathrm{Cl}^{*}$ \\
\hline Epilepsy & 3 & 0.6 & 3 & 0.4 & $1.44,0.29-7.16$ & 90 & 0.2 & $2.71,0.85-8.58$ & 87 & 0.4 & $1.54,0.49-4.88$ \\
\hline Migraine & 9 & 1.9 & 7 & 1.0 & $1.86,0.69-5.04$ & 725 & 1.9 & $1.00,0.52-1.95$ & 518 & 2.5 & $0.77,0.40-1.50$ \\
\hline Panic disorder & 4 & 0.8 & 2 & 0.3 & $2.89,0.53-15.84$ & 210 & 0.6 & $1.54,0.57-4.17$ & 203 & 1.0 & $0.88,0.32-2.37$ \\
\hline Diabetes mellitus & 3 & 0.6 & 4 & 0.6 & $1.08,0.24-4.84$ & 229 & 0.6 & $1.06,0.34-3.32$ & 140 & 0.7 & $0.95,0.30-3.01$ \\
\hline Hyperthyroidism & 3 & 0.6 & 0 & 0.0 & NA & 142 & 0.4 & $1.71,0.54-5.39$ & 75 & 0.4 & $1.79,0.56-5.69$ \\
\hline Hypertension, essential & 19 & 4.0 & 32 & 4.7 & $0.85,0.47-1.51$ & 1,592 & 4.2 & $0.96,0.61-1.53$ & 939 & 4.5 & $0.90,0.56-1.43$ \\
\hline Hypotension, essential & 13 & 2.8 & 29 & 4.3 & $0.63,0.33-1.23$ & 1,265 & 3.3 & $0.83,0.47-1.44$ & 505 & 2.4 & $1.15,0.66-2.01$ \\
\hline $\begin{array}{l}\text { Conduction disorders in heart } \\
\text { and cardiac dysrhythmias }\end{array}$ & 10 & 2.1 & 1 & 0.1 & $14.65,1.87-114.86$ & 156 & 0.4 & $5.27,2.76-10.06$ & 89 & 0.4 & $5.09,2.63-9.85$ \\
\hline Varicose veins of lower legs & 8 & 1.7 & 7 & 1.0 & $1.65,0.60-4.59$ & 566 & 1.5 & $1.14,0.57-2.31$ & 298 & 1.4 & $1.20,0.59-2.43$ \\
\hline Thrombophlebitis & 10 & 2.1 & 17 & 2.5 & $0.84,0.38-1.85$ & 978 & 2.6 & $0.82,0.44-1.54$ & 313 & 1.5 & $1.43,0.76-2.71$ \\
\hline Hemorrhoids & 23 & 4.9 & 30 & 4.4 & $1.11,0.63-1.93$ & 1,624 & 4.3 & $1.15,0.76-1.76$ & 734 & 3.5 & $1.42,0.93-2.17$ \\
\hline Asthma bronchiale & 3 & 0.6 & 11 & 1.6 & $0.39,0.11-1.40$ & 486 & 1.3 & $0.50,0.16-1.55$ & 213 & 1.0 & $0.62,0.20-1.96$ \\
\hline Constipation, severe & 17 & 3.6 & 10 & 1.5 & $2.50,1.13-5.50$ & 799 & 2.1 & $1.75,1.07-2.85$ & 420 & 2.0 & $1.83,1.12-3.00$ \\
\hline Adverse allergic drug reaction & 4 & 0.8 & 3 & 0.4 & $1.92,0.43-8.63$ & 187 & 0.5 & $1.74,0.64-4.69$ & 81 & 0.4 & $2.21,0.81-6.06$ \\
\hline
\end{tabular}

${ }^{*}$ Adjusted for the age, parity (birth order), employment status of mothers

Bold numbers show significantly higher prevalence 
Wolff-Parkinson-White syndrome and another pregnant woman was recorded with unspecified atrioventricular block. Of 17 case mothers with severe constipation, all were treated by drugs: 9 by senna, 7 by phenolphthalein and 1 woman by lactulose.

The drugs used at least by 3 case mothers during the critical period of ASD-II were evaluated on the basis of medically recorded data in the logbook. Of 43 drugs, one: phenolphthalein showed association with the higher risk of ASD-II. Of 472 case mothers, 7 (4, 0.8\%), of 678 matched control mothers, 1 (1, 0.1\%; OR with 95\% CI: 5.7, 1.3-62.9), of 38,151 population control mothers, 274 (47, 0.1\%; 35.5, 1.8-14.2) and of 21,022 malformed controls, 191 (58, 0.3\%; 2.1, 1.1-8.8). OR was calculated for the critical period of ASD-II and phenolphthalein was used for the treatment of severe constipation.

Finally, the periconceptional use of folic acid and folic acidcontaining multivitamins was evaluated (Table 2). Only one kind of tablets containing $3 \mathrm{mg}$ of folic acid was available during the study period. Hungarian obstetricians recommended 1-3 tablets for pregnant women during the study period, thus, the daily dose of folic acid was between 3-9 mg, but about $60 \%$ of women used $6 \mathrm{mg}$. The dose of folic acid was between 0.1 and $1.0 \mathrm{mg}$ in the frequently used multivitamins, in general, one tablet was used daily. The lowest proportion of folic acid supplementations during pregnancy was found in mothers of cases with ASD-II, and this pattern was seen after the use of folic acid during the first trimester. Nearly half of these women started to use folic acid in preconception period. The protective effect of medically recorded folic acid use in the prenatal maternity logbook for ASD-II was confirmed at comparison of case mothers with matched control mothers and population control mothers. This protective effect did not reach the level of significance at the comparison of case mothers and malformed control mothers.

The use of folic acid containing multivitamin supplementations showed a similar trend but significant protective effect was seen only when case mothers and matched controls mothers were compared. However, OR were $0.42,0.57$ and 0.83 at the comparison of medically recorded multivitamin supplementation in early pregnancy between case mothers and matched, population and malformed controls mothers, but CI was wide due to the limited number of pregnant women.

\section{DISCUSSION}

The aim of the study was to estimate the possible association between maternal exposures and birth prevalence of cases with ASD-II. Three risk factors: acute pelvic inflammatory diseases, chronic paroxysmal supraventricular tachycardia and phenolphthalein use showed association with a higher risk of ASD-II. Furthermore, this study was the first to show the protective effect of high doses of folic acid alone for a certain part of ASD-II.

Pelvic inflammatory diseases include the inflammatory conditions of ovary, fallopian tube, pelvic cellular tissue, and peritoneum, frequently associated with endometritis, cervitis and/or vulvovaginitis. Both acute and chronic manifestations of this disease-group are known, however, only acute diseases were evaluated in the study with 3 main symptoms: bilateral adnexal and cervical motion tenderness, cervical discharge and fever; in addition, laboratory tests show elevated count of white blood cell and sedimentation rate (21). A large number of microorganisms have been implicated as the cause of pelvic inflammatory diseases such as Chlamydia trachomatis, Neisseria gonorrhoeae, endogenous anaerobic and aerobic bacteria, genital mycoplasma etc. (22). This finding confirmed the results of our previous study (23) based on the same HCCSCA data set. The Baltimore - Washington Infant Study found an association of maternal urinary tract infections with some types of CHDs such as ASD (24).

Our previous study showed an association of paroxysmal supraventricular tachycardia with higher risk of septal defects in the heart (25). This study confirmed the association between this cardiac dysrhythmia and ASD-II indicating that some developmental disturbance in the septum may be a subthreshold manifestation of ASD-II in mothers. This finding is in agreement with the previous reports on familial atrial septal defect with prolonged atrioventricular conduction $(26,27)$.

Table 2. Frequency of pregnancy supplement uses in the mothers of cases, matched and population controls, in addition malformed controls

\begin{tabular}{|c|c|c|c|c|c|c|c|c|c|c|c|}
\hline \multirow[t]{2}{*}{$\begin{array}{l}\text { Pregnancy } \\
\text { supplements }\end{array}$} & \multicolumn{2}{|c|}{$\begin{array}{l}\text { Case mothers } \\
\qquad(\mathrm{N}=472)\end{array}$} & \multicolumn{2}{|c|}{$\begin{array}{l}\text { Matched control } \\
\text { mothers } \\
(\mathrm{N}=678)\end{array}$} & \multirow[t]{2}{*}{ OR, $95 \% \mathrm{Cl}^{*}$} & \multicolumn{2}{|c|}{$\begin{array}{l}\text { Population control } \\
\text { mothers } \\
(\mathrm{N}=38,151)\end{array}$} & \multirow[t]{2}{*}{ OR, $95 \% \mathrm{Cl}^{*}$} & \multicolumn{2}{|c|}{$\begin{array}{l}\text { Malformed control } \\
\text { mothers } \\
(\mathrm{N}=21,022)\end{array}$} & \multirow[t]{2}{*}{$\mathrm{OR}, 95 \% \mathrm{Cl}^{*}$} \\
\hline & No. & $\%$ & No. & $\%$ & & No. & $\%$ & & No. & $\%$ & \\
\hline Folic acid & 230 & 48.7 & 372 & 54.9 & $0.78,0.62-0.99$ & 20,775 & 54.5 & $0.79,0.66-0.95$ & 10,418 & 49.6 & $0.97,0.81-1.16$ \\
\hline I-III month & 115 & 24.4 & 206 & 30.4 & $0.74,0.57-0.96$ & 11,179 & 29.3 & $0.78,0.63-0.96$ & 5,458 & 26.0 & $0.92,0.74-1.14$ \\
\hline Folic acid ** & 120 & 25.4 & 247 & 36.4 & $0.59,0.46-0.77$ & 13,632 & 35.7 & $0.61,0.50-0.76$ & 4,472 & 21.3 & $1.26,1.02-1.56$ \\
\hline I-III month** & 63 & 13.3 & 130 & 19.2 & $0.65,0.47-0.90$ & 7,315 & 19.2 & $0.65,0.50-0.85$ & 2,372 & 11.3 & $1.21,0.93-1.58$ \\
\hline Multivitamin & 29 & 5.7 & 70 & 10.3 & $0.57,0.36-0.89$ & 2,509 & 6.6 & $0.93,0.64-1.36$ & 1,233 & 5.9 & $1.05,0.72-1.54$ \\
\hline I-III month & 14 & 3.0 & 50 & 7.4 & $0.38,0.21-0.70$ & 1,645 & 4.3 & $0.68,0.40-1.16$ & 772 & 3.7 & $0.80,0.47-1.37$ \\
\hline Multivitamin** & 15 & 3.2 & 34 & 5.0 & $0.62,0.33-1.15$ & 1,356 & 3.6 & $0.89,0.53-1.49$ & 526 & 2.5 & $1.28,0.76-2.15$ \\
\hline I-III month** & 6 & 1.3 & 20 & 2.9 & $0.42,0.17-1.06$ & 844 & 2.2 & $0.57,0.25-1.28$ & 323 & 1.5 & $0.83,0.37-1.86$ \\
\hline
\end{tabular}

${ }^{*}$ Adjusted for sex of cases/controls, in addition to the age, parity (birth order), employment status of mothers

**Supplementation was medically recorded prospectively in the prenatal maternity logbook.

Bold numbers show negative ("protective") associations 
There was another chronic disease, namely severe constipation that showed an association with higher risk of ASD-II. However, the detailed analysis of pregnant women showed that this association can be explained by the concomitant treatment of phenolphthalein, a frequently used laxative drug. Of 17 pregnant women with constipation, 4 had medically recorded phenolphthalein treatment during the critical period of ASD-II. Apart from these pregnant women, chronic constipation did not show association with higher risk of ASD-II.

The teratogenic potential of phenolphthalein was previously evaluated (28), and a higher risk of CAs was found (OR with 95\% CI: 1.3, 1.0-1.5). Of 4,479 cases with CHD, 33 (0.7\%) had mothers with phenolphthalein treatment during pregnancy but this association was not significant (OR with 95\% CI: 1.8, 0.8-4.0), however, different CHD-entities were not analyzed separately. This study shows the specific teratogenic potential of phenolphthalein in the origin of ASD-II.

Our study did not reveal the teratogenic potential of other drugs in the origin of ASD-II though previous studies found slight association of specified drugs such as antidepressant paroxetine with a higher risk of CHDs in general (29) or maternal drug use in general with the higher risk of ASD (OR with 95\% CI: 1.24, 1.04-1.48) (30). Other chemical exposures were not revealed in the mothers of cases with ASD-II (31).

Our data did not show an association between overt diabetes mellitus and ASD-II found in previous studies e.g. Ferencz et al. (12).

Finally, our data showed some preventive effect of high doses of folic acid alone for ASD-II during early pregnancy. The Hungarian randomized controlled trial (32-34) and cohort controlled trial (35) indicated previously the preventive effect of folic acid (0.8 mg) containing multivitamin supplementation during the periconception period beyond neural-tube defects for CHDs and VSD in particular. These findings were confirmed in some observational studies using multivitamins $(36,37)$. The possible preventive effect of folic acid alone for CHDs in early pregnancy was also shown in observational studies $(38,39)$. However, this is the first study that showed the preventive effect of high doses of folic acid alone for ADS-II in early pregnancy.

This study also showed some protective effect of folic acidcontaining multivitamins for ASD-II and confirmed the previously found preventive effect of this new primary preventive method for CHDs (32-37). However, this protective effect was less obvious due to the limited number of pregnant women with early multivitamin supplementation and heterogeneous components/ doses of multivitamins in the study.

Most ASD-II occur sporadically though moderate familial cluster of ASD-II was found in previous studies (40). Thus the multifactorial threshold model is the most plausible explanation for the origin of isolated ASD-II (41). Acute pelvic inflammatory disease and phenolphthalein may have a triggering effect for the genetic predisposition of ASD-II while the higher occurrence of paroxysmal supraventricular tachycardia in mothers may be connected with the genetic predisposition for ASD-II. Finally high doses of folic acid and folic acid-containing multivitamin in early pregnancy can suppress the genetic predisposition of ASD-II.

The strengths of the study are the large population-based data set of HCCSCA including 472 cases with ASD-II, 678 matched and 38,151 population controls without CAs and 21,022 malformed controls with other isolated CAs in the ethnically homogeneous Hungarian (Caucasian) population. Cases with CA were reported by medical doctors and reported diagnoses were critically checked in HCAR (15). In addition the validity of CHD-diagnoses has been improved due to the information of parents and available medical records some months after the birth in the HCCSCA data set (14) and finally due to the follow-up of our cases in cardiologic institutes and correspondence with mothers. We did our best to work with homogeneous ASD-II cases, therefore, cases with syndromic and complex CA including ASD, others types of ASD and ASD cases without surgical correction were excluded from the study. The collection of exposure data was based on multiple sources including prenatal maternity logbook which provided prospective medically recorded data. The exposure time and potential confounders were known.

However, there were some weaknesses of the study: the diagnosis of CHDs was accomplished during the study period (1980-1996), i.e. mainly before the spectacular improvement of medical technology particularly echocardiography, and the diagnosis of ASD-II was limited to the infancy period (7). The study cases with ASD-II were selected until the end of third postnatal months and later surgically corrected, that nearly all cases with most severe ASD-II cases were ascertained. Some part of exposure information was based on maternal information only. Since the birth of an infant with CA is a serious traumatic event for most mothers, they try to find a causal explanation, such as drug use during pregnancy. This is not the case after a birth of healthy babies and it may result in recall bias. Recall bias regarding drug use during pregnancy may lead to overestimation of the risk by up to a factor of 1.9 (42). Nevertheless, we can limit the recall bias by three approaches: First, the critical period of ASD-II was highlighted because we expected an underreporting of exposure in both critical and non-critical periods of ASD-II in the mothers of healthy babies (i.e. in the control group without CA). Second, the prospective and medically recorded data may serve as an independent reference standard. The separate analysis of only medically recorded exposure confirmed the previously mentioned associations. Third, the mothers of malformed controls had experienced similar traumatic events like the mothers of cases with ASD-II, thus this approach helps us to estimate the recall bias of control mothers. Therefore, we accepted association of ASD-II with medically recorded exposures, if it was found in the comparison with cases and malformed controls as well.

In conclusion, our findings showed an association of higher risk of ASD-II with acute pelvic inflammatory diseases, paroxysmal supraventricular tachycardia and phenolphthalein treatment as well as the preventive effect of high doses of folic acid in early pregnancy.

\section{Acknowledgement}

This project was supported by the Hungarian Grant Office of Scientific Committee of Health Ministry (1221-0/2008-1018EKU) and Versys Clinics, Human Reproduction Institute.

\section{Conflict of Interests}

None declared

\section{Details of Ethics Approval}

The Central Ethical Committee of the Hungarian Ministry of Health approved the revised protocol of the Hungarian Congenital Abnormality 
Registry including the method to obtain and store personal data of cases affected with congenital abnormality on the basis of mothers' informed consent (41 440/1969. IV/1). The revised protocol of the Hungarian Case-Control Surveillance of Congenital Abnormalities was approved by the Central Ethical Committee of the Hungarian Ministry of Health (333/1979, IX/8). However, we wanted to ask regional nurses to visit and question all non-respondent mothers, but the Ethical Committee allowed it only in non-respondent case mothers because they considered this follow-up to be disturbing for the parents of healthy children, i.e. non-respondent control mothers. Thus only 200 non-respondent and 600 respondent control mothers were visited at home and questioned by regional nurses as a part of two validation studies.

\section{REFERENCES}

1. Czeizel AE, Kamarás J, Balogh Ö, Szentpéteri J. Incidence of congenital heart defects in Budapest. Acta Paediatr Acad Sci Hung. 1972;13(3):191202.

2. Hoffman JI, Kaplan S. The incidence of congenital heart disease. J Am Coll Cardiol. 2002 Jun 19;39(12):1890-900.

3. Calzolari E, Garani G, Cocchi G, Magnani C, Rivieri F, Neville A, et al IMER Working Group. Congenital heart defects: 15 years of experience of the Emilia-Romagna Registry (Italy). Eur J Epidemiol. 2003;18(8):77380.

4. Hoffman JI, Kaplan S, Liberthson RR. Prevalence of congenital heart disease. Am Heart J. 2004 Mar;147(3):425-39.

5. Dolk H, Loane M, Garne E; European Surveillance of Congenital Anomalies (EUROCAT) Working Group. Congenital heart defects in Europe: prevalence and perinatal mortality, 2000 to 2005. Circulation. $2011 \mathrm{Mar}$ 1;123(8):841-9.

6. Mészáros M, Nagy A, Czeizel A. Incidence of congenital heart disease in Hungary. Hum Hered. 1975;25(6):513-9.

7. Fulton DR. Congenital heart diseases in children and adolescent. In: Fuster V, Walsh A, O’Rourke RA, Poole-Wilson P, editors. Hurst's the heart. 12th ed. New York: McGraw Hill Medical; 2008. p. 1855-921.

8. Gelb BD. Genetic basis of congenital heart disease. Curr Opin Cardiol. 2004 Mar;19(2):110-5.

9. Rasmussen SA, Erickson JD, Reef SE, Ross DS. Teratology: from science to birth defects prevention. Birth Defects Res A Clin Mol Teratol. 2009 Jan;85(1):82-92.

10. Clark EB. Mechanism in the pathogenesis of congenital heart defects In: Pierpont MEM, Moller JH, editors. The Genetics of cardiovascular disease. Boston: Martinus-Nijhoff; 1987. p. 3-11.

11. Ferencz C, Rubin JD, Loffredo CA, Magee CA, editors. Epidemiology of congenital heart disease: the Baltimore-Washington infant study, 19811989. Mount Kisco: Futura; 1993.

12. Ferencz C, Loffredo CA, Correa-Villasenor A, Wilson PD, editors. Genetic and environmental risk factors of major cardiovascular malformations: the Baltimore-Washington infant study 1981-1989. Mount Kisco: Futura; 1997.

13. Vereczkey A, Kósa Z, Csáky-Szunyogh M, Urbán R, Czeizel AE. Birth outcomes of cases with isolated atrial septal defect type II - a populationbased case-control study. Acta Obstet Gynecol Scand. 2013 Jul;92(7):824-9.

14. Czeizel AE, Rockenbauer M, Siffel C, Varga E. Description and mission evaluation of the Hungarian case-control surveillance of congenital abnormalities, 1980-1996. Teratology. 2001 May;63(5):176-85.

15. Czeizel AE. First 25 years of the Hungarian congenital abnormality registry. Teratology. 1997 May;55(5):299-305.

16. Czeizel AE, Intôdy Z, Modell B. What proportion of congenital abnormalities can be prevented? BMJ. 1993 Feb 20;306(6876):499-503

17. Czeizel AE, Petik D, Vargha P. Validation studies of drug exposures in pregnant women. Pharmacoepidemiol Drug Saf. 2003 JulAug;12(5):409-16.

18. Czeizel AE, Vargha P. Periconceptional folic acid/multivitamin supplementation and twin pregnancy. Am J Obstet Gynecol. 2004 Sep;191(3):790-4.

19. Czeizel AE, Puhó EH, Ács N, Bánhidy F. Use of specified critical periods of different congenital abnormalities instead of the first trimester concept. Birth Defects Res A Clin Mol Teratol. 2008 Mar;82(3):139-46.
20. Puhó E, Métneki J, Czeizel AE. Maternal employment status and isolated orofacial clefts in Hungary. Cent Eur J Public Health. 2005 Sep;13(3):144-8.

21. Stacey CM, Munday PE, Taylor-Robinson D, Thomas BJ, Gilchrist C, Ruck F, et al. A longitudinal study of pelvic inflammatory disease. Br J Obstet Gynaecol. 1992 Dec;99(12):994-9.

22. Gjønnaess H, Dalaker K, Ånestad G, Mårdh PA, Kvile G, Bergan T. Pelvic inflammatory disease: etiologic studies with emphasis on chlamydial infection. Obstet Gynecol. 1982 May;59(5):550-5.

23. Ács N, Bánhidy F, Puhó EH, Czeizel AE. Possible association between acute pelvic inflammatory disease in pregnant women and congenital abnormalities in their offspring: A population-based case-control study. Birth Defects Res A Clin Mol Teratol. 2008 Aug;82(8):563-70.

24. Wilson PD, Loffredo CA, Correa-Villasenor A, Ferencz C. Attributable fraction for cardiac malformations. Am J Epidemiol. 1998 Sep 1;148(5):414-23.

25. Bánhidy F, Ács N, Puhó EH, Czeizel AE. Paroxysmal supraventricular tachycardia in pregnant women and birth outcomes of their children. Am J Med Genet. 2010:380-8.

26. Pease WE, Nordenberg A, Ladda RL. Familial atrial septal defect with prolonged atrioventricular conduction. Circulation. 1976 May;53(5):75962.

27. Bosi G, Sensi A, Calzolari E, Scorrano M. Familial atrial septal defect with prolonged atrioventricular conduction. Am J Med Genet. 1992 Jun 1;43(3):641.

28. Bánhidy F, Ács N, Puhó EH, Czeizel AE. Phenolphthalein treatment in pregnant women and congenital abnormalities in their offspring: A population-based case-control study. Drug Discov Ther. 2008 Dec;2(6):357-67.

29. Reis M, Källén B. Delivery outcome after maternal use of antidepressant drugs in pregnancy: an update using Swedish data. Psychol Med. 2010 Oct;40(10):1723-33.

30. Källén BAJ, Otterblad Olausson P. Maternal drug use in early pregnancy and infant cardiovascular defect. Reprod Toxicol. 2003 MayJun;17(3):255-61.

31. Tikkanen J, Heinonen OP. Risk factors for atrial septal defect. Eur J Epidemiol. 1992 Jul;8(4):509-15.

32. Czeizel AE, Dudás I. Prevention of the first occurrence of neural-tube defects by periconceptional vitamin supplementation. N Engl J Med. 1992 Dec 24;327(26):1832-5.

33. Czeizel AE. Reduction of urinary tract and cardiovascular defects by periconceptional multivitamin supplementation. Am J Med Genet. 1996 Mar 15;62(2):179-83.

34. Czeizel AE. Periconceptional folic acid containing multivitamin supplementation. Eur J Obstet Gynecol Reprod Biol. 1998 Jun;78(2):151-61.

35. Czeizel AE, Dobó M, Vargha P. Hungarian cohort-controlled trial of periconceptional multivitamin supplementation shows a reduction in certain congenital abnormalities. Birth Defects Res A Clin Mol Teratol. 2004 Nov;70(11):853-61.

36. Botto LD, Olney RS, Erickson JD. Vitamin supplements and the risk for congenital anomalies other than neural tube defects. Am J Med Genet C Semin Med Genet. 2004 Feb 15;125C(1):12-21.

37. Goh YI, Bollano E, Einarson TR, Koren G. Prenatal multivitamin supplementation and rates of congenital anomalies: a meta-analysis. J Obstet Gynaecol Can. 2006 Aug;28(8):680-9.

38. Czeizel AE, Tóth M, Rockenbauer M. Population-based case control study of folic acid supplementation during pregnancy. Teratology. 1996 Jun;53(6):345-51.

39. van Beynum IM, Kapusta L, Bakker MK, den Heijer M, Blom HJ, de Walle HE. Protective effect of periconceptional folic acid supplements on the risk of congenital heart defects: a registry-based case-control study in the northern Netherlands. Eur Heart J. 2010 Feb;31(4):464-71.

40. Whittemore R, Wells JA, Castellsague X. A second-generation study of 427 probands with congenital heart defects and their 837 children. J Am Coll Cardiol. 1994 May;23(6):1459-67.

41. Nora JJ. From generational studies to a multilevel genetic-environmental interaction. J Am Coll Cardiol. 1994 May;23(6):1468-71.

42. Rockenbauer M, Olsen J, Czeizel AE, Pedersen L, Sørensen HT; EuroMAP Group. Recall bias in a case-control surveillance system on the use of medicine during pregnancy. Epidemiology. 2001 Jul;12(4):461-6.

Received July 30, 2012 Accepted in revised form December 9, 2013 